\title{
VARGAS LLOSA, EL POLÍTICO
}

\section{Carlos Peña}

Las que aparecen como veleidades políticas de Vargas Llosa - se sostiene en este artículo- no son fruto del oportunismo ni de la reflexión teórica, sino de su fidelidad vital a una muy temprana concepción de la literatura y del oficio de escribir, la que luego desarrollará en su obra ensayística. De esa concepción derivan — señala Carlos Peña — un puñado de convicciones de amplio alcance político - la moral de la convicción en la esfera pública, el rechazo del historicismo y de cualquier teodicea mundana, la razón como un atributo limitado pero imprescindible - que más tarde son racionalizadas echando mano a las ideas de Popper y de Berlin; pero no necesariamente a las de Hayek. De todo ello —advierte Peña- no resulta ni un libertario ni un creyente liberal, sino un intelectual, ante todo, fiel a sí mismo.

Carlos Peña. Rector de la Universidad Diego Portales (Santiago-Chile), profesor de derecho en la Universidad de Chile. Sus últimas publicaciones son Rawls y el problema de la justificación en filosofia política (México: 2009); El concepto de cohesión social (México: 2010); Estudios sobre Rawls (Madrid: 2011); El conflicto de las universidades: Entre lo público y lo privado (editor con José Joaquín Brunner, Santiago: 2011). Es columnista dominical del diario El Mercurio. Carlos.pena@udp.cl. 
Debiste dedicarte a la literatura y no a la revolución, Zavalita. (M. Vargas Llosa, Conversación en La Catedral.)

$\mathrm{U}$ na de las cosas que llaman la atención al lector de la obra de Mario Vargas Llosa - quien se dispone a leerlo debe ser omnívoro porque él ha escrito de todo, o casi todo, novelas, cuentos, obras de teatro, ensayos, crítica, invectivas, diccionarios, polémicas, diarios de viaje, discursos, panfletos, columnas y declaraciones de circunstancia, y cada una de esas cosas con el mismo cuidado e igual brillo deslumbranteson los cambios de posición y de puntos de vista políticos que muestran sus textos. Según las épocas, Vargas Llosa ha defendido con parejo fervor, y con el mismo entusiasmo, la idea del escritor comprometido que imaginó Sartre; la del hombre rebelde que prefirió Camus; la del observador comprometido de Aron o Revel; el socialismo planificado; la social democracia; a veces el orden espontáneo de Hayek o el mercado de la escuela austríaca; y, habrá que decir por ahora, porque con él pareciera que nunca se sabe, el falibilismo de Popper y el pluralismo de Berlin. Fue socialista en los sesenta, socialdemócrata en los setenta, liberal en los ochenta y hoy a veces insinúa ser libertario. ¿A qué se deben esos cambios de ánimo intelectual, esos entusiasmos, que parecen llevarlo a veces a cometer errores severos ${ }^{1}$ ? ¿Acaso Mario Vargas Llosa es uno de esos blancos móviles a los que es imposible someter porque

${ }^{1}$ El más notorio de todos — por su relevancia- fueron las terminantes opiniones que vertió a propósito del asesinato del Obispo Gerardi, de Guatemala. Gerardi era un defensor de los derechos humanos y uno de los autores del informe Guatemala: Nunca más. Entonces la justicia condenó a varios militares, algunos de ellos vinculados a Alvaro Arzú, político liberal de la derecha empresarial guatemalteca. Vargas Llosa, sin embargo, prestó su aval a Maite Rico y Bertrand de la Grange (autores de ¿Quién mató al obispo? Autopsia de un crimen político, 2003) quienes dijeron que los militares habían sido víctimas de un complot en el que habrían participado los propios colaboradores en materia de derechos humanos del Obispo (2004a). Si bien Vargas Llosa usó el caso para ejemplificar la necesidad de un poder judicial independiente, apoyó de manera acrítica - y difundió internacionalmente - la tesis del libro de Rico y de la Grange, que habría sido montada por la inteligencia militar. Fue un error que denunció más tarde Francisco Goldman (2009) en una documentada crónica. Vargas Llosa - dijo Goldman - al apoyar la tesis de ese libro sin contrastarla, había sido víctima de sus prejuicios políticos. Apreciaciones igualmente críticas sobre otras opiniones de Vargas Llosa — como las loas a Thatcher por sus "épicos enfrentamientos contra los mineros"- en García (2006). 
nunca se sabe dónde están? ¿Será todo esto un síntoma de oportunismo o, al revés, uno de fidelidad? Pero, en tal caso, ¿a qué o a quién?

La lectura de su obra sugiere que las veleidades políticas que se le achacan, son en verdad exigencias de una única fidelidad: la que él profesa, con fervor casi religioso, a su idea de literatura. Si Vargas Llosa parece inconstante y voluble en política, es porque así lo demanda la fidelidad perruna y a toda prueba que él guarda hacia su oficio. Se antoja veleidoso en la política, en otras palabras, porque es fiel a sí mismo y a la idea que, ya muy joven, se hizo de su vocación y de su quehacer. Si cada hombre cuenta con un rasero que le permite medir qué es aceptable y qué no, qué cosa merece la pena y cuál es, en cambio, desdeñable, cuál digna y cuál indigna, cuál debe hacer y cuál, en cambio, omitir, ese rasero, en el caso de Vargas Llosa, no es otro que la literatura, esa solitaria, como dirá él mismo después, que lo tiraniza y lo consume. Lo anunció tempranamente, para que nadie se engañara, en una declaración fechada nada menos que en 1966, en La Habana: "El papel del intelectual en los movimientos de liberación nacional":

En el creador se plantea una verdadera duplicidad o, por lo menos, una terrible tensión: quiere ser fiel a una determinada concepción política y al mismo tiempo necesita ser fiel a su vocación. Si ambas coinciden, perfecto. Si divergen, surge la tensión, el desgarramiento. No debemos, empero, rehuir esa contradicción; por el contrario, debemos asumirla plenamente, y de nuestro mismo desgarramiento hacer literatura, crear. Es una opción difícil, torturada si se quiere, pero imprescindible. ([1966a], 1983, p. 105) ${ }^{2}$.

En suma, si Vargas Llosa es interesante como ensayista político, o como político, lo es porque esas actividades muestran la fuerza formidable de su vocación literaria. De ella surgen convicciones tempranas e inalterables; luego, ideas que las racionalizan; y, finalmente, actitudes o tomas de posición en la esfera pública.

En lo que sigue, y a fin de conferir plausibilidad a esa tesis, se analiza (1) la concepción que de la literatura y de su propia vocación posee Vargas Llosa. Como se verá, su idea de la literatura y de la servi-

${ }^{2}$ En adelante, las obras de Vargas Llosa se citarán nada más mencionando el año de edición y la página. Cada vez que la referencia aluda a otro autor se dirá explícitamente. 
dumbre del escritor hacia ella es de las más tempranas y más firmes y se encuentra formulada, ya casi en su totalidad, hacia 1966, apenas tiempo después de publicar La casa verde y antes de "La literatura es fuego" ([1967], 1983), el espléndido discurso con que recibió el Rómulo Gallegos. Esa concepción de su quehacer - la manera en que él conceptualiza su vocación - le conduce, según se analiza luego (2) a un puñado de convicciones, muy tempranas también, que estarán a la base de su comportamiento político: la ética de la convicción a la hora de escribir y de actuar en la esfera pública, el rechazo de la historia como teodicea, la defensa de una moral de los límites y el empleo de la razón como un procedimiento falible, pero indispensable. Cada una de esas convicciones, que lo pusieron en entredicho con la época en que las forjó, brota a la sombra del debate intelectual europeo (especialmente francés) y se reiteran tanto en la obra de ficción como en su trabajo ensayístico. En la tercera parte (3) se analiza la recepción que Vargas Llosa hace del trabajo de Popper y de Berlin - y la distancia temprana que toma de la escuela austríaca - como una racionalización de esas tempranas convicciones. En fin (4), se examinan algunas de sus actitudes y tomas de posición normativas e institucionales.

El análisis muestra una vida intelectual y pública guiada por la convicción literaria, por la fidelidad a la propia vocación, incluso al precio de una veleidad aparente.

\section{1}

En una conferencia dictada el 11 de agosto de 1966 "en el Paraninfo de la Universidad de la República" —según reza el papel de roneo donde ese texto ha sobrevivido- Mario Vargas Llosa expuso, quizá por primera vez, sus ideas sistemáticas acerca de la novela (1966b) ${ }^{3}$. Todas las ideas que aparecerán una y otra vez a lo largo de su obra, los temas de los que se ocupa, la novela como un sustituto de una realidad mezquina y el escritor como un rebelde que nunca se sosiega, y los autores que los ejemplifican, Victor Hugo, Flaubert, Martorell, todos los conceptos, en suma, por los que juzgará más tarde su propio compromiso político, están aquí referidos con la misma intensidad y la misma devoción con que aparecerán décadas después.

${ }^{3}$ Esa conferencia no está, sin embargo, recogida en la pormenorizada bibliografía de Oviedo (1970) ni en la de Armas (1991). 
¿Por qué hay novelistas? ¿Qué explica que algunas personas dediquen sus horas y sus días a remedar la realidad entera mediante la palabra? ¿Acaso no hay bastante en la realidad real para que, además, debamos sumarle cosas de la imaginación? Lo que ocurre, explica, es que hay hombres que no están reconciliados con el entorno histórico y a los que la realidad hiere y escuece; hombres que tienen una relación viciada con el mundo. "Así, la primera comprobación que haría yo desde el punto de vista del novelista es la de que este hombre es un rebelde, es un hombre en desacuerdo con su sociedad, o con su tiempo, o con su clase, un hombre que no está satisfecho con el mundo" (1966b, p. 4; cfr. 2009a, p. 31; 2008, p. 21; 1997, p. 14; 1971, pp. 85, 86). ¿Es entonces la novela, y la literatura en su conjunto, el refugio de eso que Hegel llamaba Alma Bella, un reducto donde se protege aquel que no es capaz de soportar la maldad del mundo y que, por eso, se inventa uno moralmente más confortable? ¿No será la novela una escapatoria para gentes demasiado débiles? En absoluto. Al representar la realidad mediante la palabra, la novela hace que los hombres tomen conciencia de sí mismos, "de sus grandezas y también de sus miserias, de sus limitaciones. Es por eso que a lo largo de toda la historia han sido casi siempre las novelas las que han cumplido un papel desmitificador, turbador, tan poderoso" (1966b, p. 19; Cfr. 1971, p. 112; en Setti, 1989, p. 234; 2008, p. 24; 2004a, p. 223; Cano, 1972, p. 41). No es casualidad que la novela presagie grandes cambios históricos: que las novelas de caballería se escriban cuando el medioevo va a desaparecer, que los escritores malditos que se solazan con "la parte más negativa y monstruosa del hombre" escriban justo antes de la Revolución Francesa, y que la gran novela rusa del XIX se redacte cuando la realidad que simulan fingir también está a punto de desaparecer (1966b, p. 20).

El novelista - aquel que ejerce la forma más excelsa de la literatura, esa que instrumentaliza a todas las demás en una forma superior de síntesis - es, por eso, un suplantador de Dios (2007a, p. XXVI; 1971, p. 86). La novela, como había sugerido Camus (2003, p. 304) desacata a la divinidad (1966b, p. 16; Cano, 1972, p. 15) y el escritor es un buitre que se alimenta de carroña, de aquellas formas que, poco más tarde, principiarán a desaparecer (1966b, p. 21; 2008, p. 24; cfr. Cano, 1972).

No hay nada entonces de mero formalismo en la novela ni en la literatura (y lo dice él, que maneja como nadie las estructuras narrativas y cuenta con la destreza de un perseguido para borrar las huellas de la 
ficción). Se trata de una forma histórica en la que se describe la realidad, transmutándola mediante una serie de técnicas (los vasos comunicantes, las cajas chinas, la muda, en las que va a insistir en el resto de su obra; véanse 1966b, pp. 22-24; 1997, pp. 145-193) gracias a las cuales los hechos se trasvisten y nos muestran que la realidad está mal hecha y que nunca podremos instalarnos con el ánimo tranquilo frente a ella.

No es difícil advertir en ese conjunto de ideas que el novelista leía el año 1966 "en el Paraninfo de la Universidad de la República", según se descifra en el papel de roneo, cuando venía de publicar $L a$ ciudad y los perros y La casa verde y comenzaba a trashumar entre América Latina y Europa, algunas de las que entonces inflamaban el debate cultural europeo, en especial francés. Y tampoco es difícil darse cuenta de cómo en estas ideas —algunas de las que acompañarán su vida intelectual hasta que, como lo veremos, las reitere, emocionado, en la ceremonia del Nobel- se nota el influjo de Sartre, es cierto, pero también el de Camus.

Sartre (Sartre, 1950) le enseñó que escribir no era un acto de distracción, una actividad lujosa y prescindible de esas que dan un respiro, distraen de las penurias de la vida y así nos permiten juntar fuerzas para los actos verdaderamente importantes. Nada de eso. Las consecuencias de la literatura podían ser tan imperecederas como disparar una pistola. A la hora de escribir, enseñaba Sartre, nadie puede lavarse las manos: no cabe más que tomar posición frente a la realidad que a cada uno le tocó en suerte. "No se hace lo que se quiere y, sin embargo, se es responsable por lo que se es" (Sartre, 1950, p. 21). La realidad no expresaba una naturaleza subyacente, sino que era una amalgama de sucesos y de fenómenos a cuya síntesis cada uno contribuía con sus actos cotidianos, haciéndola y haciéndose, eligiéndola y eligiéndose. Escribir era, pues, un acto político y no cabía más que responsabilizarse por él: el escritor estaba condenado a la responsabilidad y eludirla equivalía a querer saltar fuera de la propia sombra. "Ya que el escritor no tiene modo alguno de evadirse, queremos que se abrace estrechamente con su época; es su única oportunidad; su época está hecha para él y él está hecho para ella” (Sartre, 1950, p. 10).

De ese texto - las palabras iniciales que escribió Sartre para Los tiempos modernos - "llegué a memorizar párrafos enteros", rememoró casi treinta años después (2001, p. 46). Y es que los ensayos de Sartre, recordó a su muerte, en un amplio artículo donde la discrepancia no 
pudo ocultar la admiración por el mandarín, "quemaban las manos, las noches resultaban cortas leyéndolos" (1986, p. 234).

Entre esos ensayos se encontraba, por supuesto, ¿Qué es la literatura?, uno de los más brillantes que escribió Sartre y de los que han resistido mejor el paso de los años (y seguido alimentando subterráneamente las ideas de Vargas Llosa acerca de la literatura). "Fue de los primeros libros que leí al ingresar a la universidad en 1953, y lo releí luego por partes, muchas veces, mientras militaba en la fracción universitaria comunista de Cahuide" recordó después (1986, p. 135). No es difícil imaginar al joven Vargas Llosa encerrado en una buhardilla (donde se amontonaban panfletos y afiches a favor de Argelia y las guerras de liberación nacional, 1986, p. 241) pasando por enésima vez las páginas de ¿Qué es la literatura? que había leído en San Marcos, y subrayando una línea tras otra que la narrativa - donde, a diferencia de la poesía, las palabras no son cosas sino signos - es una actividad que permite modelar el mundo, un tráfico de mentiras que, paradójicamente, permite que la verdad pueda acontecer. Estas ideas, recordó después, estaban tan magistralmente desarrolladas que "uno sentía que le faltaba la respiración" (1986, p. 234). La literatura, escribía Sartre, y el joven Vargas Llosa leía agitado, pasando una página tras otra, es compromiso: escribir novelas tiene poderes casi metafísicos, puesto que al nombrar las cosas o los sucesos se los integra a un "espíritu objetivo" y de allí en adelante dejan de ser lo que son, y se transforman. Las palabras, enseña Sartre, son un trompo extraño que no existe sino en movimiento, que no se actualizan sino hasta el momento de ser leídas: "escribir es pedir al lector que haga pasar a la existencia objetiva la revelación que yo he emprendido por medio del lenguaje" (Sartre, 1950, p. 75). La obra de arte es así "una presentación imaginaria del mundo en la medida en que éste exige la libertad humana" (Sartre, 1950, p. 87). La novela, en especial, es un acto de recreación del mundo entero que, al apelar a la libertad del lector y ganarse su confianza, nos recuerda, una y otra vez que lo real no se muestra en la contemplación, sino que en la acción (Sartre, 1950, p. 84). Escribir es revelar el mundo y, a la vez, proponerlo como una tarea.

El lema sartriano de la literatura como compromiso fue, con frecuencia, mal leído y desplazado por una versión posterior que lo entendía como una demanda de posición política del escritor, como si éste, para estar a la altura, debiera poner la obra al servicio de una tarea 
específica. Nada de eso está en el ensayo de Sartre; aunque él mismo se encargó, en los años sesenta, de alimentar esos malos entendidos (Lévy, 2001, p. 74).

Vargas Llosa - a pesar de las apariencias - no incurrió en ellos. Si bien atribuyó ventaja moral al escritor que ponía su trabajo al servicio de la revolución, por sobre el que se empeñaba en escribir para ganar el Nobel, ambos, en la medida que concebían a la literatura como un medio, eran, a fin de cuentas, “desertores de su vocación” (Cano, 1972, p. 25). Para el escritor auténtico, reclama Vargas Llosa, la escritura es siempre un fin en sí misma (y si ella sirve a la política eso es algo que viene por añadidura, sin que siquiera el escritor se lo proponga, 2005, p. 59). Y lo mismo ocurre con el objeto literario: si no consigue dotar al material erótico o político de la objetividad que es propia de la ficción, si no logra seducir la libertad del lector con las argucias del oficio, nunca será una buena obra.

Así como rehúsa cualquier concepción instrumental de la literatura - puesto que se trata de una solitaria que consume al escritor por dentro (1997, p. 19)— también rechaza el formalismo del objeto literario desde muy temprano. De nuevo se escucha aquí a Sartre (en contra de Barthes y Tel Quel y más tarde en contra de Derrida). Las palabras deben ser transparentes, puesto que se trata de signos y no de cosas, había enseñado el mandarín (Sartre, 1950, p. 48). Concebir el objeto literario como una mera estructura de signos opacos que remiten unos a otros apuntando a una realidad que no existe, en un juego sinfín de significantes - como sugería en esos años la revista Tel Quel_- es empobrecerlo. El rechazo del formalismo, y de uno de sus herederos, el postmodernismo, subsistirá, como lo prueba el relato que hace Vargas Llosa de una conferencia de Baudrillard a la que asistió, muchísimo tiempo después, en los ochenta (2000, pp. 193 y ss.).

Así entonces no cabe duda. La concepción de la literatura — del quehacer que lo ocupa casi totalmente - es, desde muy temprano, sólo una. Se anuncia, casi resumida y como si fuera un programa de trabajo, en esa temprana conferencia de la Universidad de la República del año 1966, y se reitera después, en distintos niveles de profundidad, y con diversos énfasis, en toda su obra dedicada a la reflexión sobre el objeto literario, desde Carta de batalla por Tirant lo Blanc a La verdad de las mentiras, que escribió quitándole tiempo a las labores y a la preocupación del político que él era en los noventa, pasando por los estudios dedicados a Martorell, Onetti, Victor Hugo, Flaubert, García Márquez. 
Esa concepción tiene, por supuesto, relevancia política.

Ella constituye un núcleo de significado que orienta casi la totalidad de su quehacer vital. La suya no es una concepción que resulta de motivos puramente reflexivos, como si fuera un punto de vista disciplinario de esos que, luego de hartarse de lecturas, se defienden en los departamentos de literatura o se publican en los journals. La concepción del quehacer novelístico que, hemos visto, posee el escritor, racionaliza una vocación a la que todo se subordina, que canibaliza todo lo que toca o se le acerca.

¿De qué forma, cabe preguntarse ahora, esa concepción del quehacer literario - la racionalización que acompaña el ejercicio de su vocación - ilumina las convicciones y las ideas políticas que Vargas Llosa ha llegado a tener?

\section{2}

Hay cuatro ideas que, como grandes intuiciones, inspirarán su ideario más elaborado y sus tomas de posición en cuestiones políticas. Ellas le soplarán al oído qué dirección tomar y le ayudarán a cernir lo bueno y lo malo con que tropezará en la esfera pública. Se trata de la ética de la convicción a la hora de escribir; del rechazo del historicismo; del abandono de cualquier forma de teodicea o, si se prefiere, de la defensa de una moral de los límites; y, en fin, del postulado de una racionalidad limitada.

Son ideas contradictorias con la acción política tal cual se la concebía en los sesenta y setenta.

Vargas Llosa, que, como hemos visto, las abrigó desde temprano, debió, por eso, sentirse incómodo cuando se movía en medio de la fiebre de la época. ¿Cuál era la forma de concebir la política que entonces estaba vigente? El político es - como sugirió Maquiavelo y lo expuso después Weber - quien renuncia a perseguir sus convicciones a cualquier costo para, en cambio, dar dos pasos adelante y uno atrás, calculando las consecuencias. En él alienta también la idea del futuro y del progreso: forma parte del quehacer del político moderno creer que su acción es imprescindible para acompasar el transcurrir de los días al sentido de la historia. Por eso está dispuesto a justificar sus acciones actuales, incluso las que parecen atroces, invocando el rostro sin facciones del futuro. 
¿Cómo alguien que abrigaba una ética de la convicción a la hora de escribir, que descreía que la historia tuviera un sentido y que abogaba por una moral de los límites, podía sentirse cómodo con la fiebre política de los sesenta y principios de los setenta de la que, no obstante, seguía participando?

Era obvio que "la tensión" y el "desgarramiento" a que aludía en el texto que hizo público en La Habana, en 1966, se había ya producido, y era cuestión de tiempo que acabara en una ruptura.

Un examen más detenido de esas cuatro intuiciones así lo muestra.

La concepción de la vocación literaria como una solitaria o un vicio egoísta, que esclaviza y que somete, no admite el cálculo de consecuencias, a la hora de escribir. El escritor se debe a la solitaria y a las obsesiones que ella demanda ahogar mediante la escritura, así el cielo se venga abajo o la tierra tiemble. El rechazo de Vargas Llosa del realismo socialista - esa forma vulgar del compromiso - deriva de esta particular ética de la convicción que se reiterará casi como una letanía a lo largo de todos los años y explicará su furibunda oposición a cualquier intento de domesticar o inhibir la tarea creativa, venga él de donde venga.

La literatura, declara en 1966, es una forma de insurrección permanente y ella no admite las camisas de fuerza (1983, p. 179); el mundo socialista se dará cuenta de ello o en vez de literatura tendrá nada más que una variante de la pedagogía o de la publicidad (Cano, 1972, p. 41); por eso el enjuiciamiento de Siniavski y Daniel debe producir cólera y estupor (1983, p. 107) y la censura en la URSS que denuncia Solzhenitsin en 1967 es un absurdo deformado e injusto (1983, p. 189). De ahí la renuncia a la Casa de las Américas (1983, p. 248), la Carta a Fidel Castro reclamando por el maltrato a Padilla (1983, p. 250), la protesta por el cierre obligado de dos semanarios y la crítica y la condena al general Velasco (1983, p. 345); al general Videla (1983, p. 351) y, más tarde, a Pinochet (1994, pp. 9, 112; 1999a).

Pero ¿lo que vale para la literatura vale acaso para la política?, ¿no es la política, como había enseñado Weber, un quehacer en el que es razonable demorar las convicciones a la vista de las consecuencias?, ¿no exige la política, en ocasiones, hablar con las manos en la espalda y cruzando los dedos, para lograr los objetivos que se estiman valiosos?

La distinción weberiana — que separa las convicciones del clérigo de la responsabilidad del político- es clara desde el punto de vista 
conceptual; pero, piensa Vargas Llosa, puede ser desastrosa en la práctica.

Es verdad que Bartolomé de las Casas pudo denunciar los abusos en contra de los indígenas porque no pensó en las consecuencias que de ello se seguirían para la Corona; que Sartre se puso del lado de Argelia sin detenerse en que, al hacerlo, podía desprestigiar a Francia; y que De Gaulle no tuvo empacho en mentir a sus electores para poner fin a la guerra. Pero todos esos ejemplos muestran, precisamente, que la moral es una sola y se encuentra en ese fondo recóndito de integridad que alentó el obrar de De las Casas, Sartre o De Gaulle. El problema entonces con la distinción weberiana es que no toma para nada en cuenta a los cínicos, los frívolos y los inauténticos que hacen nata en la política del día a día, esos que piden por debajo y que, a sabiendas, borran con el codo lo que escriben con la mano embaucando, así, al electorado con mentiras y con pillerías. La distinción de Weber en la práctica - que es donde importa - ha proveído de una coartada intelectual a los inauténticos que con payasadas y desplantes dañan a la política. En manos de los pillos, la distinción de Weber se ha transformado, reclama, en una “moral de los cínicos" (1994, p. 133; 2000, p. 25).

Hacer política entonces no tiene un fondo moral muy distinto al de escribir novelas. En uno y otro caso el cálculo, las medias tintas y las verdades semiocultas deben ceder el paso "a las verdades secas y completas, por peligrosas que sean" (1994, p. 138).

Por supuesto, él tuvo ocasión de ejercitar esa moral de la convicción en la campaña presidencial de la que participó. ¿Debía o no decir la verdad acerca de la política de shock que, en su opinión, había que aplicar para sacar al Perú del marasmo? ¿Acaso no era mejor eludir esa verdad y disfrazarla para, de esa manera, no ahuyentar al electorado? (1993a, pp. 257 y ss.).

En absoluto. Había razones éticas para decir la verdad y además pragmáticas. Si no se decía la verdad ¿cómo se iba a atraer las voluntades para cambiar el feo rostro de la realidad? No cabe duda, reflexionó después, que ésa pudo haber sido una de las razones por las que fue derrotado. Y es que la política de ideas, alentada por el deber de decir la verdad, tiene una de sus manos atadas a la hora de competir. Así y todo, de ninguna manera debe concluirse que en política haya que mentir (1993a, p. 238). Y lo que vale para la política vale también para la ciencia: el científico debe decir lo que cree y, por eso, es responsable de lo 
que dice en toda circunstancia. Si no nos pudiéramos tomar las palabras del científico o el filósofo en serio - reflexiona a propósito del caso Heidegger-, entonces ¿en qué aventajaría Ser y tiempo a un culebrón?, ¿acaso la genialidad no es un agravante de los errores políticos? (1994, p. $263 ; 2011 a)$.

A lo anterior se suma el rechazo de cualquier concepción historicista.

El historicismo - la idea que el acontecer cuenta con un guión oculto, a la Hegel - es incompatible con la concepción de la literatura que desde temprano tiene Vargas Llosa. Si la historia siguiese un guión, si, a fin de cuentas, hagamos lo que hagamos el acontecer se encontrara ya prefijado por una escritura invisible que podemos esforzarnos por inteligir pero que no podemos tachar o cambiar, si las cosas fueran así, tal como lo creyeron las ideologías del progreso de Kant a Hegel o a Marx, o las ideologías del desarrollo, entonces la literatura estaría de más. Se encontraría al lado de otras actividades puramente distractivas con las que escapamos del horror doméstico o mediante las que olvidamos nuestra condición de marionetas, simples mimos de un guión que no podemos controlar (cfr. 1971, p. 270). Pero la literatura tiene sentido porque la historia es contingente, un caos informe al que la literatura intenta poner orden mostrando las casi infinitas posibilidades que la libertad hace posible:

Yo creo que no solamente la idea, sino la razón de ser de la novela es dar a los hombres un orden que les permita una cierta seguridad sobre aquello que son, sobre aquello de a donde vienen y aquello a donde van. Algo que la percepción de la dura realidad, un vértigo, un caos, un infinito, nunca da (1993a, p. 229.)

Y si la literatura rechaza al historicismo, también deniega el uso de la historia como teodicea. ¿Había que denunciar los campos de trabajo forzado de Stalin en la URSS?, preguntan Dubreuihl y Perron, los personajes de Los mandarines, esa novela documental que retrata la vida intelectual francesa de la postguerra y que él, sin duda, leyó (1971, p. 448). ¿Quizá había que tolerarlos como un paso necesario para consolidar el socialismo? Hay que denunciarlos, arguye Perron, el personaje que esconde a Camus. Y Vargas Llosa estuvo siempre de acuerdo. Esta convicción —que, como vemos, viene demandada por su concepción 
del quehacer del escritor-explica también sus puntos de vista finales respecto de la obra de Camus. Camus le había parecido a Vargas Llosa en los sesenta, en 1965 para ser más precisos (1983, pp. 15, 84), cuando Sartre era su héroe y él el "sartrecillo valiente", un escritor decaído, intimista, de estilo adocenado y dominguero, un impresionista pasmado. Años después es Camus quien tiene la razón. En 1975, y "con motivo de un atentado terrorista que hubo en Lima" (1983, p. 321), Vargas Llosa volvió a abrir las páginas de El hombre rebelde (es seguro que ya lo había leído antes, en su primera época parisina, como lo prueba la figura del novelista como deicida y como rebelde que emplea ya en 1966b) y fue una revelación. El hombre rebelde es una formidable crítica de la teodicea moderna (más encendida, más aguda y más estimulante que la Miseria del historicismo de Popper a la que más adelante nos referiremos). La utopía, explica Camus, sustituye a Dios por el porvenir, al porvenir con la moral, los valores por todo lo que sirve a ese porvenir. Y así hasta alcanzar el "asesinato lógico". "Todos los intelectuales son peligrosos [...] capaces de usar las mejores ideas para justificar las peores bribonadas" (1981, p. 209). Los campos de esclavos bajo las banderas de la libertad, las matanzas justificadas por amor al hombre. "El día en que el crimen se adorna con los despojos de la inocencia, es la inocencia la que tiene que justificarse" (Camus, 2005, p. 10).

Se trata de un rechazo moral al historicismo, al que se sumará más tarde el rechazo, por llamarlo así, epistemológico de Popper.

La defensa de una moral de los límites y el rechazo del "asesinato lógico" no significan, sin embargo, que Vargas Llosa descrea de la racionalidad, es decir, de ese sofisticado procedimiento mediante el cual intercambiamos enunciados en la confianza de que nos referimos a algo - la realidad - que procuramos describir y cambiar. Al revés de lo que sostuvieron los críticos de Tel Quel — para quienes estamos presos de un juego de signos que remiten unos a otros sin que nunca podamos leer el original_- Vargas Llosa suscribe alguna forma de realismo (hay objetos independientes de la mente), una concepción de la verdad como correspondencia y una versión procedimental de la racionalidad (la racionalidad como un método y no como una propiedad) (1992, p. 30). Por supuesto, no presume de ser filósofo; pero todas esas convicciones (que encontrarán una expresión discursiva y teórica cuando descubra a Popper) estaban ya subyacentes, desde muy temprano, en su concepción de la literatura. Y todas ellas, por supuesto, tienen importancia política. 
Gracias a que no estamos atrapados en una red de significantes que nos engañan y escamotean para siempre la realidad, el debate público tiene sentido y dar razones y recibirlas nos ayuda a discernir mejor el mundo en el que debemos vivir. La muestra más clara - y también la más irónica - de esta defensa de la racionalidad que pone a Vargas Llosa lejos del alcance del postmodernismo, son sus referencias a Baudrillard (que venían precedidas de mucho antes por las desconfianzas que le producían Barthes y el punto de vista de Tel Quel; véase Cano, 1972, pp. 19-22).

Mientras en los orígenes del capitalismo, enseña Baudrillard, los objetos se relacionan entre sí bajo el principio de equivalencia general favorecido por el dinero, en la sociedad de consumo esos mismos objetos funcionan como signos subordinados y sometidos no a la realidad que simulan nombrar, sino a un código de relaciones puramente endogámicas, que los secuestra y los condena a no significar más que aquello que el propio código, el juego sinfín de los significantes, en su pura espontaneidad, decreta. La culminación del proceso es el imperio del simulacro y de la simulación: la generación, por los modelos, de una realidad sin origen, de un hiperreal. El territorio ya no precede al mapa; es el mapa el que precede al territorio (Baudrillard, 2002, p. 10). Como lo imaginó Derrida en la différence, y late en estas ideas de Baudrillard, la presencia está postergada para siempre, los signos serían, al fin y al cabo, una puesta en escena, un engaño que nos seduce hasta que, a la hora de la muerte - el único momento de la vida que escapa al código- podamos, por fin, rehuirlos, pero sólo para que los signos insurrectos nos digan, con algo de burla, como el director de escena a los partícipes del reality show, "han vivido, creído y deseado erróneamente, como si nosotros no estuviéramos".

Cuando lo conoció en los sesenta - recuerda Vargas LlosaBaudrillard "era muy inteligente y de una soberbia soltura expositiva. Entonces parecía muy serio y no le hubiera ofendido que se lo describiera como un humanista moderno" (2000, p. 194). Pero a fines de los noventa — cuando asistió a oír una de las conferencias - su talento, "en lo que parece ser la trayectoria fatídica de los mejores pensadores franceses de nuestros días, se ha ido concentrando, cada vez más, en una ambiciosa empresa: la demolición de lo existente y su sustitución por una verbosa irrealidad" (2000, p. 195). Baudrillard (y con él Derrida) ha contribuido así a abolir "la facultad humana de discernir entre la verdad y la mentira, la historia y la ficción, y hecho de nosotros [...] piezas de 
mecano privados de libertad". Al terminar la conferencia prefirió no ir a saludar al conferencista. "No quise recordarle esos tiempos en que los libros nos exaltaban y él aún creía que existíamos" (2000, p. 197).

Las tesis de Baudrillard, y otras que se les asemejan, no sólo constituyen un error intelectual, también un acto más bien frívolo que hace del debate intelectual y del intercambio de ideas una especie de "distracción lingüística" (1992, p. 30).

Esas cuatro convicciones intelectuales - arraigadas en su concepción de la literatura y tejidas con la atmósfera cultural francesason las que explican su trayectoria política. Cuando se enemista con la izquierda, defiende la democracia liberal, condena las dictaduras, se queja del intelectual barato y abomina del postmodernismo, no está haciendo gimnasia oportunista, sino siendo fiel a esas viejas convicciones.

¿Habría, sin embargo, algún puñado de ideas sistemáticas en las que esas convicciones pudieran alojarse y encontrar una expresión intelectual más acabada?

Las encontró en la obra de Popper y de Berlin y no, como a veces él mismo dejó que se creyera, en la escuela austríaca de Von Misses o en Hayek:

Mi decepción del estatismo y el colectivismo y mi tránsito hacia el demócrata y el liberal que soy - que trato de ser- fue largo, difícil, y se llevó a cabo despacio y a raíz de episodios como la conversión de la Revolución Cubana, que me había entusiasmado al principio, al modelo autoritario y vertical de la Unión Soviética, el testimonio de los disidentes que conseguía escurrirse entre las alambradas del Gulag, la invasión de Checoeslovaquia por los países del Pacto de Varsovia, y gracias a pensadores como Raymond Aron, JeanFrançois Revel, Isaiah Berlin y Karl Popper, a quienes debo mi revalorización de la cultura democrática y de las sociedades abiertas. Esos maestros fueron un ejemplo de lucidez y gallardía cuando la intelligentsia de Occidente parecía, por frivolidad u oportunismo, haber sucumbido al hechizo del socialismo soviético, o, peor todavía, al aquelarre sanguinario de la revolución cultural china (2010c.) 
Aron y Revel le enseñaron, sobre todo, un cierto talante intelectual. Aron había denunciado, el primero de todos, al estalinismo (en $\mathrm{El}$ opio de los intelectuales sugiere, como Popper, que hay que desconfiar de las ideologías porque son inmunes a los hechos), afirmado que la historia no tenía sentido alguno (de manera que los Mesías no pasaban de ser unos embaucadores, cfr. Aron, 1946) y sugerido que una mezcla de pluralismo de valores y empirismo era la mejor filosofía para orientar la acción política (Aron, 1983). Aron le enseñó, pues, la capacidad de ir contra la corriente, no buscar el aplauso, atenerse a los hechos, prescindir de una filosofía de la historia y así y todo confiar. Revel, por su parte, de origen socialista, fue partidario férreo de la democracia liberal, crítico de las ideologías (a las que veía como una forma de dispensa, Revel, 1989, p. 144) y un intelectual público que no temía enemistarse a la hora de defender las libertades individuales. Ambos son los más sajones de los intelectuales franceses - contenidos, claros, apegados a la evidencia - y, con su ejemplo, les abrieron el camino a Popper y a Berlin (1986, pp. 172, 371).

Popper (la primera referencia a él es una pálida cita del concepto de sociedad abierta, de 1988) le permitió a Vargas Llosa racionalizar - es decir, elevar a la forma de proposiciones sistemáticas y dotadas de autoridad - las viejas convicciones que acabamos de revisar; las mismas que aparecían en la Conferencia de 1966 o en el discurso de recepción del Rómulo Gallegos.

Como se sabe, Popper (a quien Vargas Llosa principia a leer en medio de la campaña presidencial del noventa, 1993b, p. 212) se sirve de las críticas de Hume a la inducción para construir su idea de la falsabilidad. Las teorías científicas, observa Popper, se formulan como enunciados universales, que no admiten excepción. ¿Son acaso verdaderas? En absoluto, enseña el filósofo austríaco. Para que fueran verdaderas debiéramos haberlas podido verificar; pero para eso requeriríamos de un observador omnisciente que fuera capaz de observar todos los casos a los que el enunciado se refiere. Las teorías científicas entonces no son verdaderas. ¿Significa eso que vivimos en medio de un engaño y que las teorías científicas valen más o menos lo mismo que las predicciones de un brujo? No, responde Popper. No son verificables (no podemos saber que son verdaderas para todos los casos a los que, sin embargo, se refieren); pero sí podemos saber o averiguar si son falsas. Como el enunciado es universal, basta un solo caso que lo desmienta para que el enunciado se venga al suelo (cfr. Caldwell, 1991, pp. 2, 3). 
Ese análisis poseyó para Vargas Llosa la fuerza de una revelación que lo dejó endeudado para siempre con Popper (1993a, p. 224; 1992. [La versión inglesa de este trabajo en 1990c]; cfr. las críticas al planteamiento de Vargas Llosa en Gorman, 1992, p. 146 y Hudelson, 1991, p. 535).

Si Popper tenía razón, entonces la crítica y el desasosiego permanente con lo establecido, la posibilidad de dudar o sospechar incluso de lo más prestigioso o lo más sacro (incluida esa forma laica de sacralidad que es la ciencia), las funciones flamígeras de la literatura en una palabra, eran una exigencia de nuestro conocimiento además de ser, como él lo había creído siempre, una condición elemental de una vida digna. Si todas las verdades son conjeturales, hipótesis destinadas a ser falseadas, proposiciones con fecha de defunción o de vencimiento, si toda verdad "es sospechosa" (1992, p. 24) y si incluso las más firmes teorías podían obsolecer, entonces la crítica y el refunfuño de los novelistas y de los intelectuales (que él venía reclamando como cosa esencial desde los sesenta) no era una demanda puramente gremial o un reclamo de inadaptados o de fabuladores siempre adolescentes y disconformes, sino una exigencia de nuestra condición que, por eso, debía ser elevada a regla básica de la vida social.

El carácter provisional de la verdad permite abogar por la tolerancia, luchar contra el dogmatismo, detenerse, en fin, ante el secreto de cada conciencia, esmerarse en el diálogo que permitía que algunas de nuestras convicciones, incluso las que creíamos más seguras y más firmes, pudieran ser derrotadas:

La teoría de Popper sobre el conocimiento es la mejor justificación filosófica del valor ético que caracteriza, más que ningún otro, a la cultura democrática: la tolerancia. Si no hay verdades absolutas y eternas [...] todos debemos reconocer que nuestras verdades pudieran no serlo y que lo que nos parecen errores de nuestros adversarios pudieran ser verdades. (1992, p. 25.)

Pero Vargas Llosa no sólo encontró en Popper esa idea conjetural de la verdad, también halló una de las críticas más poderosas al historicismo.

Popper elabora una idea, por decirlo así, epistemológica contra la pretensión de que podemos inteligir el guión de la historia, acompasar 
nuestras acciones a su transcurso o echar mano al futuro para justificar las miserias del presente. La teodicea moderna, que elaboraron desde Kant a Hegel, no tiene cabida en un autor como Popper. Lo que ocurre, explica Popper, es que las predicciones acerca de lo que vendrá se integran también a la historia y así, poco a poco, la alteran (1992, p. 27). En la medida que el discurso humano se integra a la historia, esta última nunca es un objeto quiescente o fijo al que podamos predecir. Y de ahí que "la nuestra será siempre, por fortuna, una historia inconclusa" (2010c). Al predecir lo que vendrá o al intentar inteligir su guión oculto, la modificamos, reobramos sobre ella y así nunca podemos saber qué es lo que ocurrirá (Popper, 1957, p. XII). Nada entonces está garantizado en la historia, ni los padecimientos que nos afligen, ni la libertad de que ahora disfrutamos. Tampoco el crimen o el sufrimiento pueden justificarse apelando a la historia. Si no sabemos lo que va a ocurrir, si la historia es una improvisación que toca a mil puertas, ¿cómo podríamos esgrimirla a favor o en contra de alguien? (cfr. 1986, p. 328).

Esa concepción de la historia —como una visión apenas parcial de algo inconmensurable, una sorda que responde las preguntas que nadie le formula, según dijo Tolstoi - le parece además cercana a lo que él siempre creyó era la novela: el intento de poner orden allí donde amenaza el caos, la tentativa de conferir un lugar al hombre en medio de lo que, sin la novela, sería un puro torbellino. La historia entonces, y para qué decir la historiografía, serían, como la novela, géneros literarios, formas más o menos imaginativas y retóricas de poner orden en la suma de acontecimientos, intentos de conferir al hombre un lugar en ellos. La historiografía y la novela participarían así, en cierta medida, de los poderes de la ficción (1984, p. 9): serían discursos performativos que cuando se profieren cambian el orden de las cosas (no deja de ser irónico, por supuesto, que en una idea como esta acaba acercándose a la semiología de Barthes y a la deconstrucción de Derrida):

Eso que yo siempre creí que es la Novela, leyendo a Popper descubrí que era para él la Historia, la Historia escrita. Y que, por lo tanto, si es así, un libro como La guerra y la paz de Tolstoi no es esencialmente diferente de La decadencia y caída del Imperio Romano, de Gibbon, por ejemplo. Porque en ambos libros, uno utilizando datos objetivos de la realidad, y otro datos tomados de la imaginación, hay esa construcción artificial, esa organización artificial del mundo (1993a, p. 230; cfr. 1984, p. 9). 
En Popper también encuentra dos ideas liberales ampliamente repetidas. La de que el poder debe tener límites, porque cuando se le deja solo y a sus anchas acaba en abuso o tiranía, y la de que la felicidad, qué vale la pena en la vida y qué no, no es un asunto de los gobiernos, sino de los individuos.

Pero si Popper le confiere a Vargas Llosa la posibilidad de racionalizar sus viejas convicciones, también le permite apartarse de las ideas de la escuela austríaca y de algunas ideas de Hayek (las primeras referencias a Hayek datan de 1985, cinco años después de haber estado de fellow del Woodrow Wilson Center, donde, con certeza, lo leyó. Y su mayor influencia se acusa en los días que Hernando de Soto fue uno de sus cercanos). La distancia con Hayek (a quien nunca ha dejado, sin embargo, de admirar, 1994, p. 103, especialmente por las ideas expuestas en Hayek, $1937 ; 1945^{4}$ ) se produce en lo que atinge a las relaciones entre democracia y liberalismo y a la posibilidad de políticas redistributivas por parte del estado. En ambos aspectos esa distancia se explica por la influencia de Popper ${ }^{5}$.

Ocurre que para Popper la democracia y los ideales liberales son, hasta cierto punto, indisolubles. La libertad de crítica y los derechos civiles no constituyen una condición natural del género humano, una simple playa que aparece cuando el mar del estado se retira. Por el contrario, la crítica y la revisión de lo establecido requieren de un conjunto de instituciones, la democracia, que la hacen posible y sólo al interior de la cual pueden fructificar. Sólo la democracia permite que la libertad - que es un derecho de crítica y de intervención práctica - pueda distribuirse igualmente entre los ciudadanos y evitar que la libertad "irrestricta entre los lobos y los corderos pueda significar la desaparición de los corderos"

${ }^{4}$ En esos trabajos Hayek desarrolla la idea que el orden social es la suma de acciones individuales y de tradiciones evolutivamente probadas. Ello le permitió, en contra de Von Mises, sostener que el mercado no es un a priori y discutir la perspectiva utilitarista (Hayek, 2010, p. 110). Como es obvio, sin embargo, esa explicación causal de Hayek arriesga el peligro de confundir el plano positivo con el normativo. Explicar cómo llegamos a un cierto estado de cosas, es una cosa; discutir si ese estado es normativamente adecuado o no, es otra. Algo de este problema (la dificultad para distinguir entre la constatación de un hecho y su valoración), como se muestra luego, se filtra en las opiniones de Hayek acerca de la dictadura de Pinochet.

${ }^{5}$ La diferencia, desde el punto de vista de la filosofía política, entre Hayek y Popper, puede ser expresada así: mientras para Hayek la imagen de un orden social libre es un kosmos, para Popper es el método científico. 
(1993a, p. 233). Así entonces la libertad es indisoluble de la democracia, entendida esta última como un procedimiento para la adopción de decisiones públicas; pero también, como se verá luego, como un mecanismo de redistribución. En esto la oposición a la escuela austríaca (con algunas de cuyas ideas, sin embargo, va a coquetear cuando prologue El otro sendero de Hernando de Soto) es obvia (1999).

Ese par de ideas - la indisolubilidad entre democracia y liberalismo y la necesidad de redistribución- lo alejan, también, de Hayek.

Para Hayek no hay una asociación ni conceptual ni práctica entre el liberalismo y la democracia. El liberalismo, enseña, es la respuesta a la pregunta acerca de cuáles son los límites del poder; la democracia, en cambio, es una respuesta acerca de cuáles son los orígenes del poder. ¿Puede haber dictaduras liberales entonces? Sin duda, responde Hayek, quien, fiel a sus conceptos, no tuvo empacho en apoyar en los hechos - que es donde importa, como diría Vargas Llosa - a la dictadura de Pinochet. "Como usted comprenderá es posible que un dictador gobierne de manera liberal — declaró Hayek [...]. Yo personalmente prefiero a un dictador liberal que a un gobierno democrático carente de liberalismo". En mi experiencia —aclaró- "nunca encontré a nadie que no estuviera de acuerdo en que hubo más libertad bajo Pinochet que bajo Allende". La dictadura - declara luego de aseverar que en su opinión Chile bajo Pinochet transitará a la democracia - puede ser necesaria para construir la democracia: "Sólo así la justifico. Y la aconsejo"

${ }^{6}$ Como es fácil advertir, el punto de vista de Hayek no se limita a comentar de manera encomiástica el modelo económico ni a constatar simplemente el hecho, a su juicio inevitable, de la existencia de una dictadura en ciertos casos. Hayek va más allá: i) justifica y recomienda la dictadura dadas ciertas condiciones; ii) arguye que la cantidad de libertad puede ser mayor en una dictadura que en democracia, véase El Mercurio, 12 de abril de 1981, D8 y D9. Puede verse también la carta al London Times del 3 de agosto de 1978: "More recently I have not been able to find a single person even in much maligned Chile who did not agree that personal freedom was much greater under Pinochet than it had been under Allende" ("En fecha más reciente, no he logrado encontrar una sola persona, incluso en el difamado Chile, que no estuviera de acuerdo en que hubo mucha más libertad personal bajo Pinochet que la que había habido bajo Allende"), véase Grandin, 2006, p. 173. Cfr. Silva, 1991, p. 395; Klein, 2010, p. 120, 177 (Klein informa cómo Hayek recomendó las medidas económicas que se aplicaban en Chile a Thatcher. Esta última habría hecho ver a Hayek que en democracia no era posible hacer eso). Esta información, desgraciadamente, no aparece comentada en Caldwell (2004). 
Ese punto de vista - no sólo reconocer la necesidad fáctica de una dictadura, sino además recomendarla en ciertos casos- no es ni un lapsus ni un desvarío de Hayek, como lo prueban sus obras donde insiste una y otra vez en la distinción entre democracia y liberalismo de la que se deriva (Hayek, 2007, p. 232; Hayek, 2008. p. 141, cfr. supra nota 5).

¿Está de acuerdo Vargas Llosa con la calificación benigna que hace Hayek de la dictadura de Pinochet?

En absoluto. En su opinión la democracia nunca debe ser relativizada. La recomendación normativa de Hayek — justificar y aconsejar la dictadura en ciertos casos como la antesala de la democracia y la prosperidad - es para él inaceptable:

Si la dictadura militar fuera el camino más corto hacia el desarrollo, América Latina, con el rico prontuario de satrapías castrenses que la adornan, sería el continente de la modernidad. La verdad es que, con la única excepción del de Pinochet, que enrumbó al país por la buena senda económica, pero lo ensangrentó con horrendos crímenes y violaciones de los más elementales derechos ciudadanos, todos los otros regímenes autoritarios se caracterizaron por su corrupción e ineptitud, y empobrecieron bárbaramente a los países además de maltratar, asesinar y exiliar a sus opositores. (1998.)

$\mathrm{Y}$ - como si no hubiera quedado suficientemente claro- al recibir el Premio Irving Kristol subrayó que para el liberal que él creía ser, la libertad económica iba de la mano de la libertad política. Disociarlas, agregó, era una "peligrosa falacia":

Quienes creían que el general Pinochet era la excepción a la regla, porque su régimen obtuvo algunos éxitos económicos, descubren ahora, con las revelaciones sobre sus asesinados y torturados, cuentas secretas y sus millones de dólares en el extranjero, que el dictador chileno era igual que todos sus congéneres latinoamericanos, un asesino y un ladrón (2009b, pp. 330, 331).

Pero si no comparte ese juicio específico de Hayek respecto de la dictadura, ¿compartirá acaso la distinción conceptual entre democracia y liberalismo sobre la que se erige? 
Vargas Llosa declara no conocer esa distinción y menos la consecuencia normativa que saca Hayek de ella. El conocimiento que Vargas Llosa tiene de Hayek es más superficial que el que muestra acerca de Popper o, como veremos, de Berlin. Cuando se le interroga acerca de esas opiniones de Hayek y alguna otra de Friedman responde:

nunca apoyaron la dictadura de Pinochet, nunca apoyaron los crímenes, nunca apoyaron la desaparición de un Congreso, de elecciones libres. Nunca. Von Hayek ha defendido... Miren... No sé si han leído The Constitution of Liberty, un libro absolutamente fundamental en defensa de la cultura democrática y de la libertad económica a partir de la libertad política. Es el sustento fundamental de la idea de Von Hayek (2011b).

Por supuesto esa declaración revela un desconocimiento de Hayek puesto que es precisamente en esa obra - The Constitution of Liberty - donde se efectúa la distinción entre democracia y liberalismo (y de ella se sirve Hayek para justificar y aconsejar, en ciertos casos, las dictaduras). ¿Y si Hayek hubiera hecho declaraciones que apoyaran la dictadura? En ese caso, Vargas Llosa, siguiendo el criterio que había sentado con el caso Heidegger (el intelectual es responsable por lo que dice, 1994, p. 263; 2011a), es terminante:

Si Friedman y Von Hayek lo hicieron [apoyar una dictadura, cosa que, hemos visto, hicieron] se equivocaron. Cometieron una gravísima equivocación y hay que criticarlos por eso, porque ningún liberal debe apoyar una dictadura política. Y si lo hace se equivoca, y hay que criticarlo. Yo soy un liberal $\mathrm{y}$ nunca he apoyado una dictadura. (Texto entre corchetes agregado por mí.) (2011b.)

¿Puede haber, por su parte, programas de redistribución para promover la justicia definida como igualdad de oportunidades? En ningún caso, responde Hayek. Desde luego, la justicia supone una intervención deliberada que es posible en la interacción entre dos personas, pero no en el mercado, que es un agregado de ellas. Hay también un impedimento epistemológico: la justicia requeriría un conocimiento tan pormenorizado de bienes, acciones y de fines, que es, a fin de cuentas, imposible (cfr. Caldwell, 2004, pp. 4965-4975). Es mejor confiar en el desenvolvimiento espontáneo del orden social, enseña Hayek; las so- 
ciedades humanas son un kosmos, no un taxis. Nada de eso es endosado por el pensamiento político de Vargas Llosa, que en esto no deja lugar a equívocos. Lo prueban los laudatorios comentarios que hace a la obra de Amartya Sen. Ojalá — ruega - que los funcionarios del FMI y del Banco Mundial lean a Sen y aprendan que no se trata sólo de ortodoxia económica, sino que es necesario adoptar medidas indispensables para extender mejor el bienestar material (1999). Y es que el liberalismo va de la mano con la democracia y esta con la redistribución:

Y la democracia no es solamente libertad, sino también [...] igualdad de oportunidades. Y no hay igualdad de oportunidades cuando uno no está realmente en condiciones de ejercitar sus mínimos derechos económicos. Esto es lo que justifica y fundamenta el principio de la redistribución. Un principio que hoy en día se cree socialista, cuando, en realidad, es un principio liberal, inseparable de la tradición del pensamiento liberal. (1993a, p. 234.)

Nada hay en consecuencia de libertarianismo a la Nozick o a la Hayek en Vargas Llosa (es decir, de la idea que para que la libertad florezca hay simplemente que reducir la coacción y favorecer los intercambios voluntarios). Vargas Llosa piensa, en cambio, que es inevitable alcanzar alguna solución de compromiso entre la libertad negativa (concebida como la ausencia de coacción) y la libertad positiva (concebida, a su turno, como la distribución de posibilidades reales de participación). El libertarianismo más o menos radical inspirado en la escuela austríaca (que conoció de cerca en un puñado de jóvenes, los que, junto con apoyarlo en la campaña presidencial le enseñaron que el libertarianismo lindaba con el anarquismo y a veces con "la payasada", 1993b, p. 179) también puede incurrir en los excesos de la utopía, en los peligros de esos asesinatos lógicos que él tanto teme desde los tiempos de Camus (1993b, p. 178).

Así entonces no es cierto - no para Vargas Llosa, al menosque un liberal deba endosar la libertad concebida como ausencia de coacción haciendo la vista gorda o rechazando la libertad en sentido positivo.

Así lo prueban sus análisis acerca del pensamiento de I. Berlin, el otro de sus héroes intelectuales que le permitieron racionalizar sus más tempranas convicciones. 
Entre todas las ideas que leyó en Berlin —un héroe de nuestro tiempo, dice al presentarlo - Vargas Llosa subraya ante todo la del pluralismo de valores, la idea que los seres humanos estamos demandados, con igual fuerza e intensidad, por valores opuestos entre los que, queramos o no, debemos escoger. Hay, enseña Berlin, un conflicto irresoluble entre valores últimos, una incompatibilidad final entre bienes genuinos que no podría ser arbitrada por la razón. Aceptar esa rivalidad insalvable - que rechazan autores que inspiran casi todo el pensamiento occidental, como Kant o Aristóteles- es la diferencia que media, explicaba, entre un civilizado y un bárbaro. Al contrario de quienes son escépticos, Berlin no niega de manera terminante la posibilidad de conocer valores o bienes genuinos; tampoco afirma, como el pragmatismo radical de un Rorty, que el discurso moral constituya sólo uno entre otros varios relatos posibles de nuestra condición. Berlin afirma, al contrario de lo que haría un escéptico, que los valores son objetivamente plurales; aunque, agrega, ellos son inconmensurables y finalmente adversarios entre sí. Hay, en suma, como enseñaban Maquiavelo, Herzen, Montesquieu, Mill, verdades contradictorias (Berlin, 1992a, p. 138; 1992b, p. 194). Todas las utopías sociales en cambio, advierte Vargas Llosa, las mismas que conducen al "asesinato lógico" que denunciaba Camus (y que él leyó en sus primeros días parisinos), creen que la totalidad de los ideales humanos son posibles de congeniar, "que la satisfacción de uno o varios de estos fines no es obstáculo para materializar también los otros" (1986, p. 265).

Pero - no hay caso- es inevitable alcanzar entre los valores opuestos alguna forma de compromiso, en vez de creer que uno de ellos tiene superioridad sobre el otro o que, una vez alcanzado uno de ellos el que resta vendrá por añadidura. Esto que se dice de todos los valores, se dice también, piensa Vargas Llosa, de la libertad.

La distinción entre libertad negativa y libertad positiva — ¿habrá otra distinción conceptual más citada que esta? - no tiene por objeto, sugiere Vargas Llosa, mostrar que una de ellas, la positiva, es un ideal insensato o estúpido, en tanto que la otra, la negativa, es la única estimable o posible. En la práctica — de nuevo: que es donde importa— se trata de conseguir algún nivel de compromiso entre ambas libertades, entre la falta de coacción que afecta a las personas y el número de puertas que tiene abiertas ante sí: 
Las sociedades que han sido capaces de lograr un compromiso entre ambas formas de libertad son las que han conseguido niveles de vida más dignos y más justos (o menos indignos e injustos). Pero esta transacción es algo muy difícil y será siempre precaria, pues, como dice el profesor Berlin, la libertad negativa y la positiva no son dos interpretaciones de un concepto sino algo más: dos actitudes profundamente divergentes e irreconciliables sobre los fines de la vida humana. (1986, p. 271.)

Es fácil observar de qué forma las ideas de Berlin son consistentes, en la forma en que las presenta Vargas Llosa, con aquellas otras que, haciendo justicia a sus convicciones más profundas, aquellas que venían de los años sesenta, encontraron su expresión más fidedigna, según vimos, en los textos de Popper. Pero no es sólo la idea de verdades irreconciliables - que calza como un guante con el falibilismo y la crítica al historicismo de Popper - lo que de Berlin llama la atención a Vargas Llosa. Ocurre lo mismo con la idea de la historia, uno de los aspectos centrales, como vimos, de su concepción de la novela.

Desde los tiempos que leyó a Camus - y su crítica del asesinato lógico - Vargas Llosa desconfía profundamente de cualquier forma de inevitabilidad en la historia. Y es que si la historia fuera inevitable, si lo que nos acontece fuera parte de un guión que no hemos leído pero que dirige, sin que siquiera lo sepamos, nuestros actos, entonces no sólo la idea de libertad, sino también de la responsabilidad se vendría abajo. Y la novela - ese quehacer imaginativo que al poner orden en el caos nos enseña el lugar que nuestra libertad tiene en él_— sería un mero divertimento.

Pero Berlin no cree eso. Él —a quien en ocasiones Vargas Llosa llama, en expresión inmejorable, un filósofo discreto - no piensa que la historia tenga un guión inevitable y que nuestra responsabilidad en ella sea, entonces, una quimera.

Nuestro lenguaje moral, piensa Berlin, y los términos asociados a la idea de responsabilidad, no constituyen un engaño, un balbuceo ignorante - como lo sostendría un determinista - sino la muestra de una condición constitutiva. La categoría de ser humano responsable no es equivalente a la de las ninfas o los centauros, sino una descripción aproximadamente fiel, piensa Berlin, de los seres que somos. La historia constituiría el despliegue sorprendente de esa capacidad, el 
escenario en el que, de maneras inesperadas, se manifiesta esa facultad humana. Desde luego, la idea que en el curso de la historia podemos hacernos de nosotros mismos, de lo que es deseable y de lo que no lo es, y acerca de la manera en que debemos vivir, puede ser un engaño, pero nosotros somos ese engaño, no su víctima; él nos acompaña no como una vestidura que pudiésemos desprender de nosotros para, luego de eso, seguir siendo los mismos, sino que está en nosotros como una piel que, una vez desprendida, nos transforma y nos disminuye, ocultando lo que en verdad somos. Berlin cree, como Hegel, que nuestra substancia es histórica; pero suscribe la opinión de Herzen de que no posee teleología alguna y que equivale, por decirlo así, a una improvisación que toca a mil puertas (Berlin, 1974, pp. 33, 88). Y en ella, lee Vargas Llosa, el papel de la individualidad, como los personajes en una novela, es insustituible:

Ni la formidable, y durante un buen tiempo, solitaria resis-
tencia británica contra el nazismo hubiera sido lo mismo
sin Wiston Churchill, ni el New Deal - el gran experimento
social del Nuevo Trato a favor de fórmulas más igualitarias y
democráticos en Estados Unidos - lo que fue, sin Franklin
Délano Roosevelt, ni el sionismo moderno y la creación del
Estado de Israel hubieran tenido las características que tuvie-
ron sin Hayyim Weizmann. $(1986$, p. 276.)

¿Cuál es la posición política de quien sustenta esas convicciones y esas ideas? Si en materia política hay convicciones (un fondo último que orienta la trayectoria vital) e ideas (la racionalización de esas convicciones), también hay actitudes o tomas de posición, normativas e institucionales, frente a la vida que tenemos en común.

¿Cuáles son las tomas de posición de Vargas Llosa?

El escritor peruano, que suele ser aplaudido por la derecha, ha adoptado posiciones que, sin embargo, a la derecha latinoamericana le provocan escozor.

Es partidario del reconocimiento pleno de los gays (aunque les recuerda que la ausencia de prohibición podría matar el deseo, 1994, p. 233); de la despenalización de la droga (no es capaz de entender la prohibición de fumar marihuana si no se daña a terceros) (2010b); no 
vacila a la hora de distribuir la píldora del día después (de hecho ha defendido la despenalización del aborto y considera igualmente arbitrario obligar a abortar que coaccionar a alguien a mantener un embarazo, 2000, p. 250); aboga por la más amplia autonomía expresiva (y esa es una de las razones para oponerse a cualquier forma de proteccionismo en el ámbito de la cultura, 1994, p. 265; 1986, p. 313); considera al nacionalismo una variante de la barbarie y junto a la religión lo culpa de las peores carnicerías de la historia (otra de las ideas cuya racionalización final encontró en Berlin [1994, pp. 49, 169; cfr. 2010c)]; es partidario de la neutralidad religiosa más estricta (al extremo que ha defendido las sectas poniéndolas al mismo nivel que la Iglesia Católica, 2000, p. 159); y, como vimos, es partidario, sin ninguna atenuante, de la democracia y los derechos humanos (cree que los golpes de estado son un producto latinoamericano tan nefasto como la coca; aunque esta última sería algo menos dañina, 1994, p. 109).

Esas tomas de posición derivan del falibilismo y de la tolerancia. Si el guión de la vida humana no está previamente escrito y si nuestras convicciones, incluso las más básicas, están amenazadas por el error, si todas nuestras verdades son, como vimos, sospechosas de embuste, entonces parece mejor dejar una esfera de autogobierno en el que cada uno pueda tomar el riesgo y libremente decidir.

Pero las actitudes políticas no se agotan nada más que en los puntos de vista estrictamente normativos (aunque ellos sean tan radicales y limpios como los de Vargas Llosa). Ellas también se refieren al tipo de instituciones básicas que se promueven.

Fuera de la preferencia por la democracia (a la que, como se vio, imagina de la mano con el liberalismo alejándose así de Hayek) Vargas Llosa no se ha ocupado de cuestiones institucionales. Quizá la única ocasión en que lo hizo de manera más persistente fue cuando se acercó a Hernando de Soto (o, más bien, éste se acercó a él). De esa colaboración salió el prólogo a El otro sendero (en Setti, 1989), un libro en el que se aplican al Perú las tesis de la economía neoinstitucional: la idea que el subdesarrollo proviene de la falta de instituciones imparciales y bien diseñadas que sustituyan la confianza personal y disminuyan los costos de transacción. En el Perú, y en el resto de América Latina, explica Vargas Llosa, nunca hubo genuino capitalismo, esa ascesis y racionalización de la ganancia. Para que existiera se requerirían instituciones imparciales y firmes que aseguraran derechos de propiedad e 
intercambios voluntarios. Todo eso ha brillado por su ausencia y en su lugar ha habido mercantilismo, es decir, una falla del proceso político que permite que los grupos de presión, o las minorías consistentes, hagan suyo el bienestar en perjuicio de las mayorías. ¿Bastará entonces con reglas claras y limpias para que la prosperidad pueda florecer? ¿Tenía entonces razón la escuela austríaca al insistir en la necesidad de que la espontaneidad del intercambio aflore? En absoluto, preocupado siempre de que las ideas funcionen en la práctica — que es donde importa-, Vargas Llosa se ha opuesto también a todo dogmatismo en esta materia y ha abogado por una mejor redistribución de bienes y de capacidades:

Es natural que en un país del Tercer Mundo con las desigualdades económicas, la falta de integración cultural y los problemas sociales del Perú, el Estado tenga una función redistribuidora que cumplir [...]. Con los desequilibrios actuales entre pobres y ricos, serranos y costeños, urbanos y rurales, quechuahablantes e hispanohablantes, las medidas mejor concebidas y más puras tienden invenciblemente, en la práctica, a favorecer a pocos y perjudicar a muchos. (En Setti, 1989, p. 203.)

¿Un creyente libertariano, un true believer liberal, un hombre de derechas como a veces se le presenta?

En absoluto.

Un indócil que, una vez que pasan los primeros entusiasmos, vuelve a ser fiel a ese joven de bigotito, con aspecto de galán de fotonovelas, engominado y fumador, que en el año 1966, y con dos espléndidos libros a sus espaldas, leía una Conferencia en el "Paraninfo de la Universidad de la República". Un inútil que para lo único que sirve - como suele regañarlo su mujer, según recordó llorando, al recibir el Nobel- es para escribir.

\section{REFERENCIAS}

Altares et al. Semana de autor: Mario Vargas Llosa. Madrid: Ediciones de Cultura Hispánica, 1989.

Armas Marcelo, J. Vargas Llosa: El vicio de escribir. Madrid: Norma, 1991.

Aron, R. Introducción a la filosofía de la historia. Buenos Aires: Losada, 1946. - El observador comprometido. Buenos Aires: Emecé, 1983.

Baudrillard, J. Cultura y simulacro. Barcelona: Kairós, 2002. 
Berlin, I. Libertad y necesidad en la historia. Madrid: Revista de Occidente, 1974.

- Contra la Corriente: Ensayos sobre historia de las ideas. México: FCE, 1992a.

- "Herzen y Bakunin y la libertad individual". Pensadores rusos. México: FCE, 1992b.

Caldwell, B. "Clarifying Popper". Journal of Economic Literature, Vol. 29, № 1 (marzo 1991), pp. 1-33.

- Hayek's Challenge. An Intellectual Biography of F. A. Hayek. The University Chicago Press (Amazon Kindle), 2004.

Camus, A. El hombre rebelde. Buenos Aires: Losada, 2005.

Cano, R. El buitre y el ave fénix: Conversaciones con Mario Vargas Llosa. Madrid: Anagrama, 1972.

De Beauvoir, S. Los mandarines. Buenos Aires: Sudamericana, 1971.

García, A. "Mario Vargas Llosa y el compromiso del intelectual". El Viejo Topo, 219 (abril 2006).

Goldman, F. El arte del asesinato político: ¿Quién mató al Obispo? Barcelona: Anagrama, 2009.

Gorman, D. et al. "Vargas Llosa and Popper". PMLA, Modern Language Association, Vol. 107, No 1 (enero 1992), pp. 146-147.

Grandin, G. Empire's Workshops. Latin America, the USA and the Rise of the New Imperialism. New York: Metropolitan Books, 2006.

Hayek, F. "Economics and Knowledge". Economica, New Series, Vol. 4, No 13 (febrero 1937), pp. 33-54.

"The Use of Knowledge in Society". The American Economic Review, Vol. 35, № 4 (septiembre 1945), pp. 519-530.

- Letter. Times, 11 de julio de 1978.

"En el momento actual nuestra principal tarea es limitar el poder del gobierno". El Mercurio de Santiago, 12 de abril de 1981, D8 y D9.

"Principios de un orden social liberal". En F. Hayek, Estudios de filosofía, política y economía. Madrid: Unión Editorial, 2007.

- Los fundamentos de la libertad. Madrid: Unión Editorial, 2008.

Hayek sobre Hayek (edición de Kresge y Wenan). Madrid: Unión Editorial, 2010.

Hudelson, R. "On Mario Vargas Llosa on Truth and Freedom". PMLA, Modern Language Association, Vol. 106, № 3 (mayo 1991), pp. 534-535.

Klein, N. La doctrina del schock. Buenos Aires: Paidos, 2010.

Lévy, B. H. El siglo de Sartre. Barcelona: Ediciones B, 2001.

Oviedo, J. M. Mario Vargas Llosa: La invención de una realidad. Barcelona: Seix Barral, 1970.

Popper, K. The Poverty of Historicism. New York: Routledge \& Kegan Paul, 1957.

The Open Society and its Enemies, Tomos I y II. New Jersey: Princeton University Press, 1971.

Revel, J. F. El conocimiento inútil. Buenos Aires: Planeta, 1989.

Sartre, J. P. ¿Qué es la literatura? Buenos Aires: Losada, 1950. 
Setti, R. Diálogo con Vargas Llosa: Ensayos y conferencias de Vargas Llosa. Buenos Aires: Intermundo, 1989.

Silva, P. "Technocrats and Politics in Chile: From the Chicago Boys to the CIEPLAN". Journal of Latin American Studies, Vol. 23, № 2 (mayo 1991), pp. 385-410.

Vargas Llosa, M. "El papel del intelectual en los movimientos de liberación nacional”, 1966a. (Recogido en Contra viento y marea, 1962-1983, Vol. I. Barcelona: Seix Barral, 1983).

Conferencia dictada en el Paraninfo de la Universidad de la República, en documento a roneo bajo el título "La Novela", Montevideo, Cuadernos de Literatura, Fundación de Cultura Universitaria, 1966b.

"La literatura es fuego". Discurso de recepción del Premio de Novela Rómulo Gallegos, en Caracas, 1967. (Recogido en Contra viento y marea, 1962-1983, Vol. I. Barcelona: Seix Barral, 1983).

- García Márquez: Historia de un deicidio. Barcelona: Seix Barral Editores, 1971.

- La guerra del fin del mundo. Madrid: Seix Barral, 1981.

Contra viento y marea, 1962-1972. Vol. I. Barcelona: Seix Barral: 1983.

Historia de Mayta. Madrid: Alfaguara, 1984.

Contra viento y marea II, 1972-1983, Vol. II. Barcelona: Seix Barral, 1986.

- Contra viento y marea III, 1964-1988. Barcelona: Seix Barral, 1990a. La orgía perpetua: Flaubert y Madame Bovary [1975]. Barcelona: Seix Barral, 1990b.

“Updating Popper". PMLA, Modern Language Association, Vol.

105, No. 5 (octubre (1990c), pp. 1018-1025.

"Karl Popper al día". Vuelta, № 184 (1992), pp. 24-33.

“Mi deuda con Karl Popper". En Schwartz (ed.), Encuentro con Karl

Popper. Madrid: Alianza Editorial, 1993a.

- El pez en el agua: Memorias. Barcelona: Seix Barral, 1993b.

- Desafios a la libertad. Madrid: Aguilar (1994).

Cartas a un joven novelista. Madrid: Ariel, 1997.

"Vejez intranquila". Caretas N 1502, 6 de febrero de 1998.

"El caso Pinochet". La Nación, 20 de octubre, 1999a.

"Pan y libertad". La Nación, 17 de noviembre de 1999b.

El lenguaje de la pasión. Madrid: Ediciones El País, 2000.

Historia secreta de una novela. Barcelona: Tusquets, 2001.

La tentación de lo imposible. Buenos Aires: Alfaguara, 2004a.

“¿Quién mató al Obispo?” El País, 22 de febrero de 2004 (2004b).

Literatura y política. México: FCE, 2005.

"Cien años de soledad. Realidad total. Novela total". En Gabriel

García Márquez, Cien años de soledad, Real Academia de la Lengua Española, Edición Conmemorativa, 2007a. 
“Jean-Francois Revel". Letras Libres, noviembre 2007 (2007b).

Carta de batalla por Tirant lo Blanc. Lima: Santillana, 2008.

El viaje a la ficción: El mundo de Juan Carlos Onetti. Montevideo:

Santillana, 2009a.

- Sables y utopías. Madrid: Aguilar, 2009b.

Diccionario del amante de América Latina. Barcelona: Paidos, 2009c.

- Sueño y realidad de América Latina. Barcelona: Seix Barral, 2010a.

“Avatares de la marihuana". El País, 3 de junio de 2010 (2010b).

"Elogio de la lectura y la ficción". El País, 8 de diciembre de 2010 (2010c).

"Los réprobos". El País, 30 de enero de 2011 (2011a).

"Los socialdemócratas tienen debilidades colectivistas". Página 12, 22 de abril de 2011 (2011b). 